\title{
Combined effects of ultra-high pressure homogenization and short-wave ultraviolet radiation on the properties of cloudy apple juice
}

\author{
J.N. Sauceda-Gálvez a , I. Codina-Torrella a , M. Martinez-Garcia a , M.M. Hernández-Herrero a , \\ R. Gervilla ${ }^{\mathrm{b}}$, A.X. Roig-Sagués ${ }^{\mathrm{a}, *}$

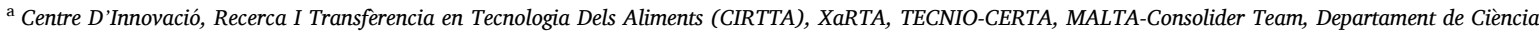 \\ Animal I Dels Aliments, Facultat de Veterinària, Universitat Autònoma de Barcelona, 08193, Bellaterra, Spain \\ b SPTA-Servei Planta Tecnologia Aliments, Universitat Autònoma de Barcelona, C/ de L'Hospital S/N, 08193, Bellaterra, Barcelona, Spain
}

\section{A R T I C L E I N F O}

\section{Keywords:}

$\mathrm{UHPH}$

UV-C

apple juice

Physicochemical properties

Sensory evaluation

\begin{abstract}
A B S T R A C T
This work addresses the physicochemical, enzymatic and sensory changes in cloudy apple juice treated by ultrahigh pressure homogenization (UHPH) and short-wave ultraviolet radiation (UV-C) applied at $20{ }^{\circ} \mathrm{C}$. Those technologies were applied in single and combined treatments at different UHPH pressures (200-300 MPa) and UV-C doses (14.3-27.8 J/mL). UV-C treatments could not effectively inactivate enzymes, but treatments at 300MPa UHPH reduced pectin methylesterase activity to a $24.6 \%$, and polyphenol oxidase activity was not detected. Those samples presented a higher antioxidant capacity ( $283 \%$ measured by FRAP, and $286.4 \%$ by DPPH) than in non-treated juice, and after a combination with $28.7 \mathrm{~J} / \mathrm{mL}$ of UV-C the polyphenols content augmented to $277.6 \%$. Sensory evaluation revealed that UHPH at $300 \mathrm{MPa}$ and UV-C at $21.5 \mathrm{~J} / \mathrm{mL}$ significantly changed perceptible odour and overall flavour of cloudy apple juice, while treatments at $200 \mathrm{MPa}$ didn't produce any significant changes in the different parameters. The results obtained in this study give a promising perspective of what a combination of both technologies can bring about in terms of obtaining stabilized fruit juices with improved antioxidant activity and polyphenol availability.
\end{abstract}

\section{Introduction}

Apple juices in markets are most likely processed by heattechnologies like thermal pasteurisation in order to prevent them from deterioration by enzymes such as polyphenol oxidase (PPO) and pectin methylesterase (PME) (Krapfenbaue et al., 2006; Suárez-Jacobo et al., 2012) or from the growth of microorganisms naturally present in fruits (Suárez-Jacobo, Gervilla, Guamis, Roig-Sagués, \& Saldo, 2010). Thermal technologies can address these problems, but they have a negative impact in some of the characteristics of juices like changes in their organoleptic properties (colour, aroma, flavour) (Carbonell, Navarro, Izquierdo, \& Sentandreu, 2013) as well as in their vitamin content (Velázquez-Estrada, Hernández-Herrero, Rüfer, Guamis-López, \& Roig-Sagués, 2013).

There are non-thermal technologies for liquid-food processing currently on investigation. Ultra-high pressure homogenization (UHPH) works by forcing a liquid through a narrow gap in a pressure intensifier (Dumay et al., 2013) and it has been proved to inactivate microbial cells by a conjunction of stresses (turbulence, cavitation, shear stress) that provoke different types of damages on the cell wall of microorganisms, and proved to inactivate enzymes like polyphenol oxidase and pectin methylesterase in apple juice (Suárez-Jacobo et al., 2012) while preserving most of the antioxidant activity and phenolic components. However, it is ineffective against bacterial spores when the treated matrix is at low inlet temperatures $\left(20-50{ }^{\circ} \mathrm{C}\right.$ ) (Reverter-Carrión et al., 2018).

Short wavelength ultraviolet radiation (UV-C) is another emerging technology currently under study. It can penetrate microorganisms, including bacterial spores (Reverter-Carrión et al., 2018), and form pyrimidine dimers in DNA preventing it from replicating and consequently causing death of the cell (Sauceda-Gálvez et al., 2019). UV-C also spares most of the original characteristics of fruit juices and vitamin content (Koutchma, 2009). Unfortunately, UV-C is ineffective in inactivating PME (Torkamani \& Niakousari, 2011) unless juices are irradiated for longer periods at high doses (Falguera, Pagán, \& Ibarz, 2011).

\footnotetext{
* Corresponding author.

E-mail address: arturxavier.roig@uab.cat (A.X. Roig-Sagués).
} 
Recent investigations point out that UHPH and UV-C technologies can be used together in order to inactivate fungal and bacterial spores, UV-C can inactivate pressure-tolerant spores, while UHPH can inactivate some microorganisms that are resistant to radiation or make them more vulnerable to it (Reverter-Carrión et al., 2018; Sauceda-Gálvez et al., 2019). In them it was observed that there was an additive or synergic effect. But there is no much information about the impact that both technologies can have on the physicochemical properties of foods when used together.

The objective of this research was to elucidate the effect that a combination of different pressures of UHPH and UV-C doses have on physicochemical properties of a cloudy apple juice, as well as on its naturally present detrimental enzymes, and moreover, how each technology affects the sensory attributes of this product.

\section{Materials and methods}

\subsection{UHPH treatments}

UHPH treatments were done in a UHPH homogenizer (model A) (Ypsicon S. L., Barcelona, Spain) of $60 \mathrm{~L} / \mathrm{h}$ capacity with needle and seat model Ultra Shear Valve (Ypsicon S.L., Barcelona, Spain). The homogenization pressures for these experiments were of 200 and $300 \mathrm{MPa}$. The inlet temperature of the process was of $24 \pm 2{ }^{\circ} \mathrm{C}$ and the volume of juice was $13 \mathrm{~L}$. The residence time at the valve was of $0.7 \mathrm{~s}$, the temperature at the valve at $200 \mathrm{MPa}$ was of $77 \pm 1{ }^{\circ} \mathrm{C}$, and of $107 \pm 1.5^{\circ} \mathrm{C}$ at $300 \mathrm{MPa}$. Outlet temperature was of $32 \pm 2{ }^{\circ} \mathrm{C}$. The juice was immediately cooled down to $20^{\circ} \mathrm{C}$ by water bath before the combined treatments with UV-C. Samples for analysis were frozen at $-80{ }^{\circ} \mathrm{C}$ in $50-\mathrm{mL}$ Falcon tubes. Samples for particle size and sensory analysis were refrigerated at $4{ }^{\circ} \mathrm{C}$ up to $24 \mathrm{~h}$.

\subsection{UV-C treatments}

UV-C treatments were done in a $70 \mathrm{~mL}$ capacity thin film $(1 \mathrm{~mm})$ concentric-type reactor (UV-Therm, Ypsicon) that consisted in a feeding tank connected to a UV-C lamp (55W) (LAB81055 NNI 150/76 XL, UVConsulting Peschl España, Geldo, Spain) coated with a quartz tube and a measured irradiance of $31 \mathrm{~mW} / \mathrm{cm}^{2}$ at a wavelength of $254 \mathrm{~nm}$ by an UVM-CP handheld radiometer and a calibrated sensor (90155, UVConsulting Peschl, Mainz, Germany). The apple juice was pumped through the reactor at different speeds to be irradiated in the doses of $14.3,21.5$ and $28.7 \mathrm{~J} / \mathrm{mL}$. The temperature of the whole process was of $20 \pm 0.5{ }^{\circ} \mathrm{C}$. Samples were frozen at $-80{ }^{\circ} \mathrm{C}$ in $50 \mathrm{~mL}$ falcon tubes. Samples for particle size and sensory analysis were refrigerated at $4{ }^{\circ} \mathrm{C}$ up to $24 \mathrm{~h}$.

\subsection{Apple juice physicochemical characterization}

Raw fresh-pressed cloudy apple juice (Golden delicious var.) was provided by a local producer. The juice was characterized in different physicochemical parameters before and after treatments.

\subsubsection{Absorption coefficient}

Absorption coefficient at $254 \mathrm{~nm}$ wavelength $\left(\alpha_{254}\right)$ was measured at $20{ }^{\circ} \mathrm{C}$ by spectrophotometer NanoPhotometer Pearl (IMPLEN GmbH, München, Germany) and a quartz cuvette (Fisher Scientific, Hanover, Illinois, USA) of $10 \mathrm{~mm}$ depth, and it was reported as $\mathrm{cm}^{-1}$.

\subsubsection{Turbidity, $\mathrm{pH}$ and ${ }^{\circ}$ Brix}

Turbidity was measured in nephelometric turbidity units (NTU) with a turbidimeter Hach 2100 Q (Hach Lange Spain, L'Hospitalet de Llobregat, Spain).

$\mathrm{pH}$ was measured with a pH-meter pH básico-20 (Crison, Barcelona, Spain), and ${ }^{\circ}$ Brix by a Spectronic Instruments refractometer (Rochester, N.Y., USA) at $20^{\circ} \mathrm{C}$.

\subsubsection{Colour}

Colour was measured by a colorimeter (MiniScan XETM, Hunter Associates Laboratory Inc., Reston, USA.), using the CIELAB colour space which comprises $L^{*}$ (lightness), $a^{*}$ (red to green) and $b^{*}$ (yellow to blue) coordinates. The total colour difference $\left(\Delta E^{*}\right)$ between the raw juice and treated samples was calculated following the formula (Velázquez-Estrada, Hernández-Herrero, Guamis-López \& Roig-Sagués, 2019):

$\Delta E^{*}=\left[\left(\Delta L^{*}\right)^{2}+\left(\Delta a^{*}\right)^{2}+\left(\Delta b^{*}\right)^{2}\right]^{1 / 2}$.

\subsubsection{Particle size distribution}

Particle size distribution was measured by a Mastersizer Micropulus 2.15 (Malvern Instruments, Inc., Works, United Kingdom), a laser diffraction particle size analyzer. Samples were diluted in distilled water until optimal obscuration level for the laser (5-15\%). An optical model based on Mie scattering theory by spherical particles was applied using the following conditions: refractive index for the dispersed phase = 1.471; refractive index of dispersion phase (water) $=1.334$. The size distribution was characterized by the mean diameters $\mathrm{D}[3,2]$ and $\mathrm{D}[4$, 3].

\subsection{Enzymatic activity}

Residual activity of polyphenol oxidase (PPO) was done as explained by Cano, Hernandez, and Ancos (1997) using $37.5 \mu \mathrm{L}$ of juice filtered by syringe filters $(0.45-\mu \mathrm{m}$ pore diameter) (Labbox, Vilassar de Dalt, Spain) and $1.5 \mathrm{~mL}$ of $0.7 \mathrm{M}$ catechol (Sigma Aldrich, St. Louis, USA) in phosphates buffer ( $\mathrm{pH}$ 6.5). Samples' absorbance was read at $420 \mathrm{~nm}\left(A_{420}\right)$ wavelength by spectrophotometer (IMPLEN); absorbance changes $\left(\Delta A_{420}\right)$ were recorded before and after incubation at $20^{\circ} \mathrm{C}$ for $20 \mathrm{~min}$; $\Delta A_{420}$ of the treated samples were compared with the untreated juice (100\% PPO activity).

Residual activity of pectin methylesterase (PME) was done by adapting the method of Carbonell et al. (2013) using a solution of $1 \%$ citrus pectin (Sigma Aldrich) and $0.2 \mathrm{M}$ of $\mathrm{NaCl}$ (Sharlau, Sentmenat, España). pH was adjusted to 8.0 with $\mathrm{NaOH} 4 \mathrm{~N}$ (Panreac Química SLN, Castellar del Vallès, España). The volumes used for each test were of 20 $\mathrm{mL}$ of pectin solution and $5 \mathrm{~mL}$ of sample. This mix was titrated by $0.1 \mathrm{~N}$ of $\mathrm{NaOH}$ (Panreac) by an automatic titrator Titrando 842 (Metrohm, Herisau, Switzerland) until this mix reached a $\mathrm{pH}$ of 7.8. $\mathrm{pH}$ changes were recorded during $30 \mathrm{~min}$ at $20^{\circ} \mathrm{C}$ and $\Delta \mathrm{pH} / \Delta \mathrm{t}$ of the treated samples were compared with the untreated juice (100\% PME activity).

\subsection{Non-enzymatic browning}

This essay was performed according to Meydav et al. (1977). Samples were filtered by syringe filters (Labbox) and mixed with ethanol 1:1 ratio. Samples were read by spectrophotometer (IMPLEN, GmbH, München, Germany) and results were reported as $A_{420}$.

\subsection{Antioxidant capacity}

Antioxidant capacity was performed via two methods with apple juice filtered by syringe filters (Labbox), and Trolox (Sigma Aldrich) at different concentrations $(50-1000 \mu \mathrm{M})$ as the equivalent standard. FRAP (Ferric-ion Reducing Antioxidant Power) method was based on the method explained by Benzie and Strain (1996) with the filtered juice diluted with water in a 1:1 proportion. The mix consisted on $90 \mu \mathrm{L}$ of sample or standard, $270 \mu \mathrm{L}$ of distilled water and $2.7 \mathrm{~mL}$ of FRAP reagent pre-warmed at $37^{\circ} \mathrm{C}$. Samples were stored at $37^{\circ} \mathrm{C}$ for $30 \mathrm{~min}$ and read by spectrophotometer (IMPLEN) at $593 \mathrm{~nm}$ wavelength. DPPH method (radical scavenging activity) was based on as explained by Bondet, Brand-Williams, and Berset (1997). The mix consisted in $80 \mu \mathrm{L}$ of sample and $2.92 \mathrm{~mL}$ of DPPH reagent (Sigma Aldrich). Samples were stored at 
$25{ }^{\circ} \mathrm{C}$ for $1 \mathrm{~h}$ and read by spectrophotometer (IMPLEN) at $515 \mathrm{~nm}$ wavelength. Results were expressed in Trolox equivalent $(\mu \mathrm{M})$.

\subsection{Total polyphenols}

These were measured based on the method of Singleton, Orthofer, and Lamuela-Raventós (1998). The filtered sample was diluted with distilled water in a 1:1 proportion. The mix consisted on $100 \mu \mathrm{L}$ of sample or gallic acid standard (Sigma Aldrich), $0.75 \mathrm{~mL}$ of $0.2 \mathrm{~N}$ Folin-Ciocalteau (Sigma Aldrich), and $0.75 \mathrm{~mL}$ of $6 \%$ sodium carbonate anhydrous (Panreac). Samples were read by spectrophotometer (IMPLEN) at $760 \mathrm{~nm}$. Results were expressed as gallic acid equivalent in $\mathrm{mg} / \mathrm{L}$.

\subsection{Sensory evaluation}

Sensory evaluation was carried according to ISO 8587:2006 which describes a method that allows to sort a series of samples in rank order based on the intensity of a single attribute or an overall (ISO 8587:2006). This test can determine differences between the samples, but not the degree of difference. In order to find which parameters had significant differences among the samples, $F_{\text {test }}$ had to be obtained through the formula:

Ftest $=\left(\frac{12}{j \cdot p(p+1)}\right)\left(R 1^{2}+R 2^{2}+R 3^{2}+R 4^{2}\right)-3 j(p+1)$

Where: $j=$ number of judges; $p=$ number of different samples; $R 1-R 4$ $=$ total score of the sample. For a test of these characteristics if $F_{\text {test }}>$ 7.81 it means that there were significant differences among the samples.

A group of 21 tasters (judges) from CIRTTA-UAB scored samples coming from the untreated juice, UHPH treated juice at 200 and 300 $\mathrm{MPa}$, and UV-C treated juice at $21.5 \mathrm{~J} / \mathrm{mL}$.

\subsection{Statistic analysis}

Experiments were performed three times and from each experiment duplicate samples were analysed $(n=6)$. Averages, standard deviations and analysis of variance (ANOVA) were done by using the linear models (GLM) via software (Statistica ver 7 , StatSoft, Inc). Tukey test was employed for comparisons between samples means. Differences were considered as significant when $p<0.05$.

\section{Results and discussion}

\subsection{Samples characterization and changes after treatments}

Treatments by UHPH greatly changed $\alpha_{254}$ in cloudy apple juice reaching the maximum values after $300 \mathrm{MPa}$ (Table 1 ). This might have happened due to the fragmentation of particles and from the liberation of soluble solids as it could be seen in Table 1 that there was an increase in turbidity and ${ }^{\circ}$ Brix in comparison with the untreated control. Contrary to this, ${ }^{\circ}$ Brix faced a reduction after 200-MPa UHPH. Velázquez-Estrada, Hernández-Herrero, Guamis-López, and Roig-Saguès (2019)

Table 1

Characterization of cloudy apple juice samples from Control and UHPH treatments at 200 or $300 \mathrm{MPa}$. The measured parameters are separated by columns and from left to right: absorption coefficient at $254 \mathrm{~nm}\left(\alpha_{254}\right)$, Turbidity (NTU), $\mathrm{pH}$ and ${ }^{\circ}$ Brix. Lowercase letters for each parameter mark significant differences $(p<0.05)$ between samples means obtained by Tukey test.

\begin{tabular}{lllll}
\hline $\begin{array}{l}\text { Sample } \\
\text { UHPH }\end{array}$ & $\alpha_{254}$ & NTU & $\mathrm{pH}$ & ${ }^{\circ}$ Brix \\
\hline $0 \mathrm{MPa}$ & $11.54^{\mathrm{c}} \pm 0.3$ & $2356.61^{\mathrm{c}} \pm 12.85$ & $3.91 \pm 0.02$ & 11.9 \\
$200 \mathrm{MPa}$ & $49.27^{\mathrm{b}} \pm 0.44$ & $3307.06^{\mathrm{b}} \pm 3.19$ & $3.92 \pm 0.02$ & 11.2 \\
$300 \mathrm{MPa}$ & $61.93^{\mathrm{a}} \pm 0.69$ & $2641.89^{\mathrm{a}} \pm 1.77$ & $3.94 \pm 0.01$ & 12 \\
\hline
\end{tabular}

also noticed a similar behaviour in filtered orange juice after UHPH treatments at different pressures (100-300 MPa), though they observed an increase in ${ }^{\circ}$ Brix after $100 \mathrm{MPa}$, and a decrease after $300 \mathrm{MPa}$, which is in contrast with our results, but this could be due to the properties of the matrices used in both experiments. Many of the changes found here could be observed presumably because of the high content of suspended particles in cloudy apple juice being affected by the different UHPH treatments (Fig. 1 and Fig. 2).

Average $\mathrm{pH}$ values slightly augmented after UHPH treatments (Table 1). Experiments on clear apple juice by Suárez-Jacobo et al. (2011) show that there was a small increase in pH after $300 \mathrm{MPa}$. On the other hand, Velázquez-Estrada et al. (2019) reported no significant changes in filtered orange juice's pH treated by UHPH (100-300 MPa).

The increase in turbidity is in consonance with the results of Velázquez-Estrada et al. (2019) who observed higher cloudiness in orange juice after UHPH treatments (100-300 MPa). The highest turbidity values were seen in the treatments of UHPH at $200 \mathrm{MPa}$, and these were even higher than in samples of $300 \mathrm{MPa}$. This could be because turbidity is a relative measure of light scattering which is more related to the optical effects of suspended matter than to mass concentration (Davies-Colley \& Smith, 2001). From these results it could be said that particles in apple juice changed after UHPH treatments in different ways according to the pressure. This reasoning could be supported by particle size-results (Fig. 1).

According to data in Fig. 1, there were differences between samples treated by UHPH at 200 and $300 \mathrm{MPa}$, where the size and distribution of particles changed differently after the two assayed pressures resulting in smaller particle sizes than in juices non-treated by UHPH. The increase of turbidity of UHPH-processed samples (Table 1) might have been influenced by this phenomenon. Particles from samples treated at 300 MPa present an important size distribution in the range of smaller than $2 \mu \mathrm{m}$ diameter. These results can be contrasted with those of Donsì, Esposito, Lenza, Senatore, and Ferrari (2009) in UHPH-treated apple juice (Annurca var.) in which treatments at $300 \mathrm{MPa}$ diminished particle size with a larger distribution of particles measuring $11-\mu \mathrm{m}$ diameter, they observed product destabilization during storage at $37^{\circ} \mathrm{C}$. Cloud stability is much influenced by the presence of particles smaller than 2 $\mu \mathrm{m}$ diameter (Betoret E., Betoret N., Carbonell \& Fito., 2009). Larger particles, like those ones from the control and UV-C samples, tend to settle down by gravity (Velázquez-Estrada et al., 2019). After UHPH treatments, $\mathrm{D}[3,2]$ and $\mathrm{D}[4,3]$ values decreased significantly $(p<0.05)$ (Fig. 2). High $\mathrm{D}[3,2]$ values relate to the potential of interaction between particles and higher chances to form aggregates, while high values of $\mathrm{D}[4,3]$ indicate that particles are heavier and tend to settle down during storage (Velázquez-Estrada et al., 2019).

From these results it could be expected that UHPH-processed apple juice at $300 \mathrm{MPa}$ would remain more cloud-stable than in 200-MPa or non-UHPH treated samples.

There were no significant changes from UV-C treatments in any of the previous parameters, and consequently these data were not shown in tables or figures.

\subsection{Residual enzyme activity}

Polyphenol oxidase in cloudy apple juice increased its activity $87 \%$ after 200-MPa UHPH (Fig. 3) compared with the untreated control. Previous experiments on clarified apple juice (Saldo, Suárez-Jacobo, Gervilla, Guamis, \& Roig-Sagués, 2009) report that PPO seems not to be inactivated after UHPH treatments of 100-300 MPa. Some other authors observed higher PPO activity after high-pressure treatments (Cano et al., 1997), and it has also been stated that any damage to cells can result in the release of enzymes (Chisari, Barbagallo, \& Spagna, 2007). On the other hand, there was no PPO activity detected in juices processed at 300-MPa UHPH (Fig. 3), that could have happened due to the loss of the enzyme's native structure because of the intensity of the mechanical forces at the pressure valve (Bot et al., 2018), and because of the 


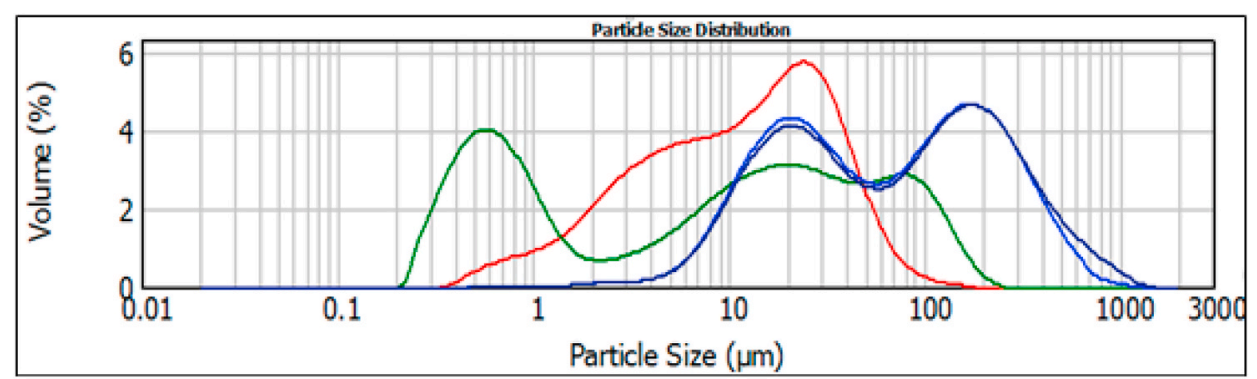

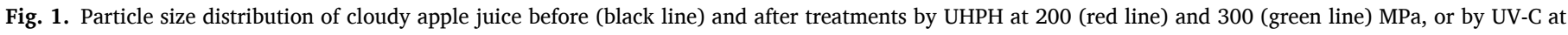

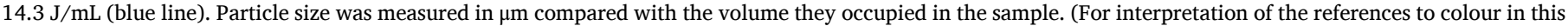
figure legend, the reader is referred to the Web version of this article.)

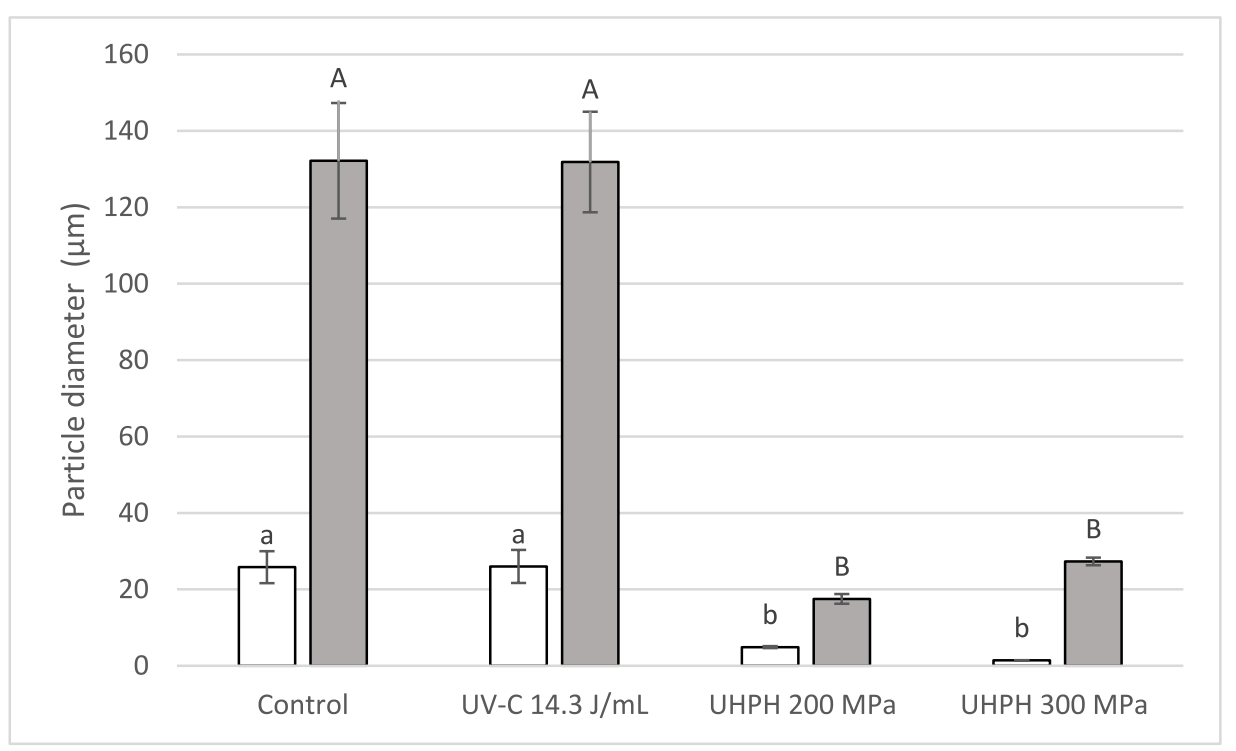

Fig. 2. Particle diameters from cloudy apple juice treated by UHPH at 200 and $300 \mathrm{MPa}$ or by UV-C at $14.3 \mathrm{~J} / \mathrm{mL}$. Sauter diameter (surface-weighed mean diameter) $\mathrm{D}[3,2]$ (white bars) is influenced by smaller particles, and $\mathrm{D}[4,3]$ (volume-weighed mean diameter) (grey bars) is usually affected by bigger particles. Lowercase letters mark significant differences $(p<0.05)$ between sample means of D $[3,2]$, and capital letters mark significant differences $(p<0.05)$ between sample means of D[4, 3] both obtained by Tukey test. Error bars mark the standard deviation of the samples.

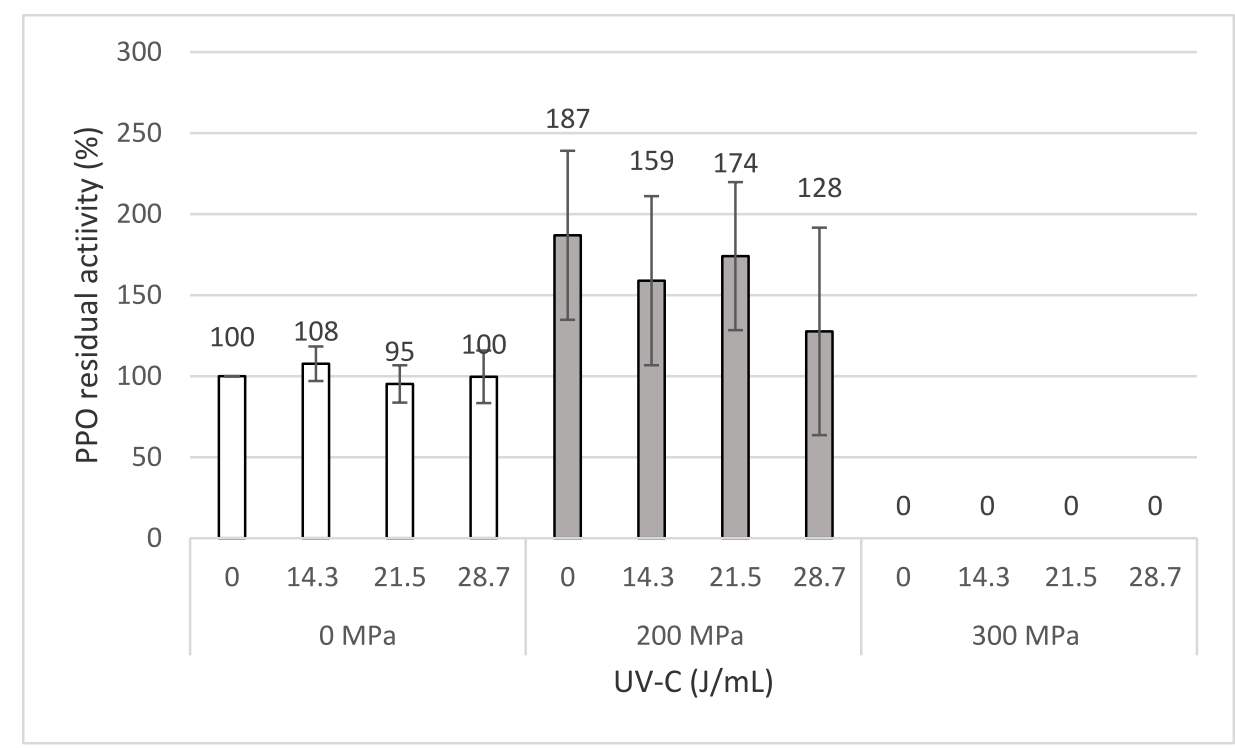

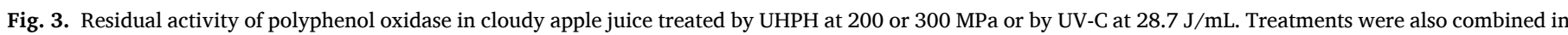
the order UHPH $\rightarrow$ UV-C. Error bars mark the standard deviation of the samples.

temperature reached there $\left(107 \pm 1.5^{\circ} \mathrm{C}\right)$ when the juice was passing through, that temperature was considerably higher than in the treatment at $200 \mathrm{MPa}\left(77 \pm 1{ }^{\circ} \mathrm{C}\right)$. PPO activity in 200-MPa treated juice decreased after UV-C treatments. A reduction of PPO activity by UV-C has been reported as well by other authors in clarified apple juice (Falguera et al., 2011). Interestingly, PPO activity seemed to remain 


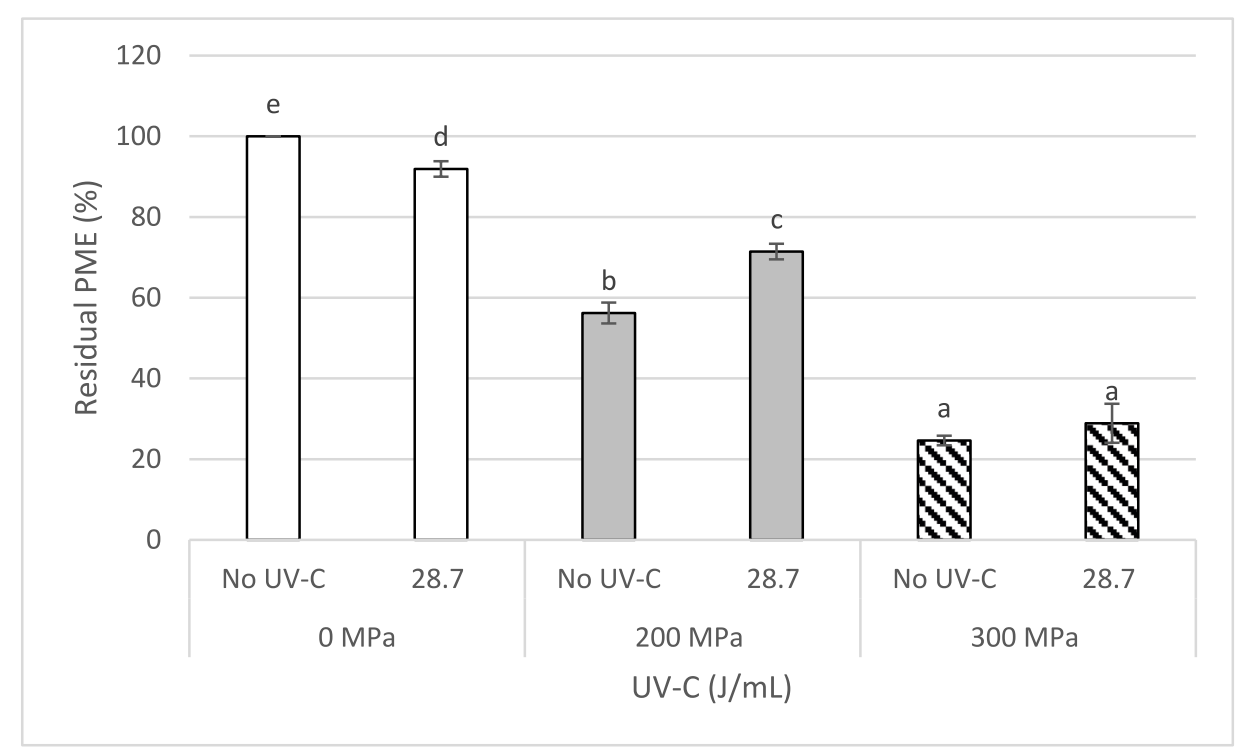

Fig. 4. Residual activity of pectin methylesterase in cloudy apple juice treated by UHPH at 200 and $300 \mathrm{MPa}$ or by UV-C at $28.7 \mathrm{~J} / \mathrm{mL}$. Treatments were also combined in the order UHPH $\rightarrow$ UV-C. Lowercase letters mark significant differences $(p<0.05)$ between samples means obtained by Tukey test. Error bars mark the standard deviation of the samples.

stable after UV-C single treatments, probably because of the possible damage to cells provoked by hydro-dynamical stresses and the release of enzymes into the matrix as explained by Orlowska, Koutchma, Kostrzynska, Tang, and Defelice (2014) who observed an increase in PPO activity in raw cloudy apple juice after a UV-C treatment of $44.5 \mathrm{~mJ} / \mathrm{cm}^{2}$ in a Taylor-Couette reactor.

UHPH treatments at 200 and $300 \mathrm{MPa}$ considerably inactivated PME (Fig. 4), with a residual PME activity (RPME) of $56.2 \%$ after a $200 \mathrm{MPa}$ treatment, but yielding the best results at $300 \mathrm{MPa}$ with a RPME activity of $24.6 \%$. These results can be compared with those from a similar experiment reported by Velázquez-Estrada, Hernández-Herrero, Guamis-López, and Roig-Sagués (2012) with filtered orange juice treated by UHPH which explains that PME can be better inactivated as the pressure increases, but there is also a contrast in between their results and those obtained here with apple juice. In their experiments they observed that after a treatment of 200 or 300 MPa the RPME activity was less than $10 \%$. This could be attributed to the different matrices used in both experiments and the ratios between thermolabile and thermostable types of PME that can differ even among varieties of the same fruit (Krapfenbauer, Kinner, Gössinger, Schönlechner, \& Berghofer, 2006).

In UV-C treatments PME activity was slightly reduced by $28.7 \mathrm{~J} / \mathrm{mL}$ of UV-C with an average of $91.9 \%$ RPME activity (Fig. 4). Other experiments with apple juice (Starking var.) show that after $40 \mathrm{~min}$ of exposure to a UV-C lamp PME was completely inactivated (Falguera et al., 2011), but in their experiments PME content in juice was already low because the clarification treatment (centrifugation) separated the juice from the pulp that was discarded along with most of the enzymes (PME) already acting on it. Experiments with other fruit juices like orange juice that passed through a thin film reactor showed a low PME inactivation after a treatment of $73.8 \mathrm{~mJ} / \mathrm{cm}^{2}$ with a RPME activity of 92\% (Torkamani \& Niakousari, 2011).

UV-C $(28.7 \mathrm{~J} / \mathrm{mL})$ applied after a UHPH treatment of $200 \mathrm{MPa}$ did not contribute to a greater inactivation of PME. In fact, there was a significant increase $(p<0.05)$ of PME activity. Its residual activity after a single UHPH treatment of $200 \mathrm{MPa}$ was of $56.2 \%$, but the same sample exposed to UV-C had an increase in RMPE activity back to $71.4 \%$ (Fig. 4). There were no significant differences with the results coming from the treatment of UHPH at $300 \mathrm{MPa}$ and with its combination with UV-C.

Table 2

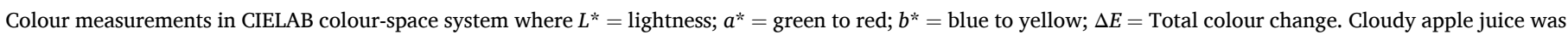

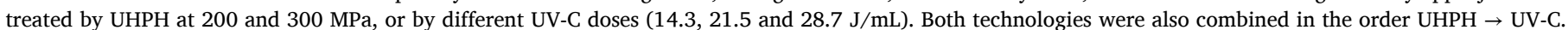
Lowercase letters for each value mark significant differences $(p<0.05)$ between samples means obtained by Tukey test.

\begin{tabular}{|c|c|c|c|c|c|}
\hline \multicolumn{2}{|c|}{ Treatment } & \multirow[t]{2}{*}{$L^{*}$} & \multirow[t]{2}{*}{$a^{*}$} & \multirow[t]{2}{*}{$b^{*}$} & \multirow[t]{2}{*}{$\Delta E$} \\
\hline UHPH & UV-C $(\mathrm{J} / \mathrm{mL})$ & & & & \\
\hline \multirow[t]{4}{*}{$0 \mathrm{MPa}$} & 0 & $25.13^{\mathrm{a}} \pm 0.66$ & $13.5^{\mathrm{a}} \pm 0.73$ & $26.59 \pm 1.26$ & $0^{\mathrm{a}}$ \\
\hline & 14.3 & $27.01^{\mathrm{b}} \pm 0.57$ & $14.51^{\mathrm{a}} \pm 0.18$ & $26.71 \pm 0.59$ & $2.24^{\mathrm{b}} \pm 0.36$ \\
\hline & 21.5 & $26.62^{\mathrm{b}} \pm 0.36$ & $13.74^{\mathrm{a}} \pm 0.54$ & $26.29 \pm 2.11$ & $2.44^{\mathrm{b}} \pm 0.75$ \\
\hline & 28.7 & $27^{\mathrm{b}} \pm 0.67$ & $13.45^{\mathrm{a}} \pm 0.73$ & $26.41 \pm 1.06$ & $2.15^{b} \pm 0.66$ \\
\hline \multirow[t]{4}{*}{$200 \mathrm{MPa}$} & 0 & $31^{\mathrm{c}} \pm 0.58$ & $11.19^{b} \pm 0.3$ & $25.74 \pm 2.24$ & $6.64^{c} \pm 1$ \\
\hline & 14.3 & $31.03^{c} \pm 0.11$ & $11.22^{\mathrm{b}} \pm 0.31$ & $25.61 \pm 1.48$ & $6.54^{c} \pm 0.3$ \\
\hline & 21.5 & $31.43^{c} \pm 0.27$ & $11.37^{\mathrm{b}} \pm 0.67$ & $26.14 \pm 1$ & $6.75^{c} \pm 0.34$ \\
\hline & 28.7 & $31.49^{c} \pm 0.39$ & $12.16^{\mathrm{b}} \pm 0.74$ & $25.4 \pm 1.48$ & $6.76^{c} \pm 0.48$ \\
\hline \multirow[t]{4}{*}{$300 \mathrm{MPa}$} & 0 & $45.05^{d} \pm 0.12$ & $8.41^{c} \pm 0.17$ & $31.38^{\mathrm{a}} \pm 0.7$ & $21.12^{\mathrm{d}} \pm 0.15$ \\
\hline & 14.3 & $45.34^{d} \pm 0.24$ & $7.74^{c} \pm 0.9$ & $30.99^{\mathrm{a}} \pm 1.13$ & $21.51^{\mathrm{d}} \pm 0.23$ \\
\hline & 21.5 & $45.84^{d} \pm 0.8$ & $7.68^{c} \pm 0.96$ & $30.36^{\mathrm{a}} \pm 1.63$ & $21.91^{\mathrm{d}} \pm 0.59$ \\
\hline & 28.7 & $45.95^{d} \pm 1.08$ & $7.35^{c} \pm 0.86$ & $31.09^{\mathrm{a}} \pm 1.28$ & $22.22^{\mathrm{d}} 0.95$ \\
\hline
\end{tabular}




\subsection{Colour and non-enzymatic browning}

These experiments demonstrated that UV-C and UHPH treatments caused significant changes $(p<0.05)$ in apple juice's colour parameters, principally in the $L^{*}$ value (Table 2 ) which represents the lightness. This value increased more with UHPH treatments (at both pressures) than with UV-C. Velázquez-Estrada et al. (2019) also reported an increase of lightness in orange juice after UHPH treatments, which is positively correlated to cloudiness, a decrease of particle size and a consequent increase of light diffraction. An increment of the $L^{*}$ value after UV-C exposure of centrifuged apple juice (Golden delicious var.) was also observed by Falguera et al. (2011). UHPH treatments also decreased $a^{*}$ value meaning that the product was less red than the original one and the samples treated only by UV-C. The $b^{*}$ value significantly changed only after $300 \mathrm{MPa}$ of UHPH treatment. Compared with the untreated juice, overall colour change $(\Delta E)$ was significantly different in all treatments and it became higher in the samples treated by UHPH, being the combined treatment of $300 \mathrm{MPa}$ with $28.7 \mathrm{~J} / \mathrm{mL}$ of UV-C (Table 2) the one which changed the most, probably due to browning changes and particle size and distribution. UV-C increased $\Delta E$ slightly after UHPH treatments, but these changes were not significant.

Apple juice's browning index after $300 \mathrm{MPa}$ of UHPH and combinations with UV-C presented a lower value than in the untreated juice (Fig. 5), the evolution of browning is related to an increase of $a^{*}$ because of the appearance of melanoidins (Ibarz, Pagán, Panadés, \& Garza, 2005), and probably UHPH was capable to degrade these compounds. These results were in consonance with those of Saldo et al. (2009) who observed a reduction of $a^{*}$ value after submitting clarified apple juice to a treatment of $300 \mathrm{MPa}$ of UHPH. The other significant difference found was on the treatment of UV-C at $14.3 \mathrm{~J} / \mathrm{mL}$, but browning index kept increasing with higher doses.

\subsection{Antioxidant capacity}

Fig. 6 shows that antioxidant capacity measured by FRAP and DPPH assays, as well as polyphenols content increased considerably in samples treated by UHPH at $300 \mathrm{MPa}$ compared with the untreated control (a $283 \%$ when measured by FRAP, and a $286.5 \%$ by DPPH). This might have happened due to the disruption of suspended particles (cells) and the liberation of antioxidant compounds. Similar experiments carried out with clear apple juice (Suárez-Jacobo et al., 2011) demonstrated that UHPH (100-300 MPa) did not affect the antioxidant capacity in this juice, though there were no differences between the treated samples and the control. UV-C treatments seemed to slightly increase the availability of polyphenols according to FRAP assay, being the samples treated by 21.5 and $28.7 \mathrm{~J} / \mathrm{mL}$ statistically different than the untreated juice. There were no differences detected by DPPH method in the aforementioned UV-C treatments. The antioxidant activity in apples is mostly given because of its content in polyphenols (Suárez-Jacobo et al., 2011). Samples processed by $200 \mathrm{MPa}$ of UHPH did not show any improvement in polyphenols content despite their reduction in particle size (Figs. 1 and 2). This probably happened because polyphenols were affected by PPO which was not inactivated but even made more available into the matrix by a $200 \mathrm{MPa}$ treatment (Fig. 3). On the other hand, UV-C treatments in raw juice and in the juice treated at $300 \mathrm{MPa}$ seemed to lower down the total polyphenol content with a dose of $14.3 \mathrm{~J} / \mathrm{mL}$, but it increased after 21.5 and $28.7 \mathrm{~J} / \mathrm{mL}$ treatments (Fig. 6). Samples treated by UHPH at $300 \mathrm{MPa}$ and combined with UV-C showed that there was a decrease in the antioxidant capacity with higher doses when analysed by FRAP assay, but differences were not significant according to DPPH assay. These antioxidant capacity-measuring methods work under different principles, FRAP assay measures the capacity to reduce ferric-ions, and DPPH assay measures the capacity to scavenge free radicals. It is recommendable to use more than one type of antioxidant assays so as to have a better elucidation of the total antioxidant activity of the sample (Velázquez-Estrada et al., 2013).

\subsection{Sensory evaluation}

The results of the test of preference are shown in Fig. 7. Samples were scored by the judges according to their preference. If the minimal significant difference (MDS) between two samples in a test of this magnitude is higher than 16.4, it could be said that samples were significantly different. This was observed in the parameters of odour and overall flavour and results were detailed in Table 3. Raw juice was better preferred than the treated ones at most parameters, and it was significantly better in flavour and odour compared with juices after UV-C $(21.5 \mathrm{~J} / \mathrm{mL})$ and a pressure of $300 \mathrm{MPa}$ because de difference between scores surpassed MDS value (Table 3). Even though there were significant changes in overall flavour, the treated samples were all similar to

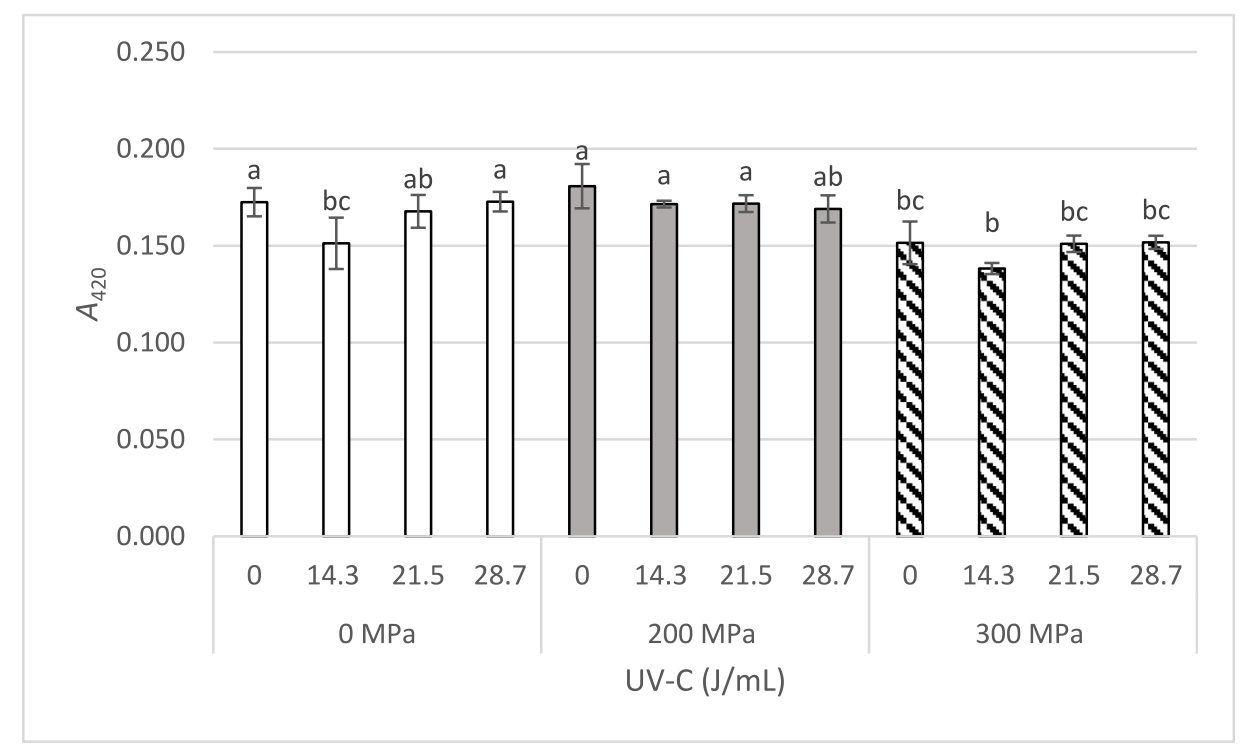

Fig. 5. Browning index measured at $A_{420}$ of cloudy apple juice treated by UHPH at 200 and $300 \mathrm{MPa}$, or by different UV-C doses (14.3, $\left.21.5 \mathrm{and} 28.7 \mathrm{~J} / \mathrm{mL}\right)$. Both

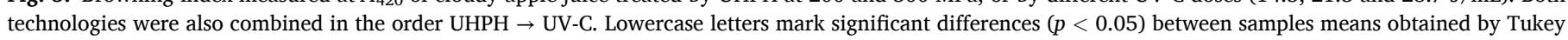
test. Error bars mark the standard deviation of the samples. 


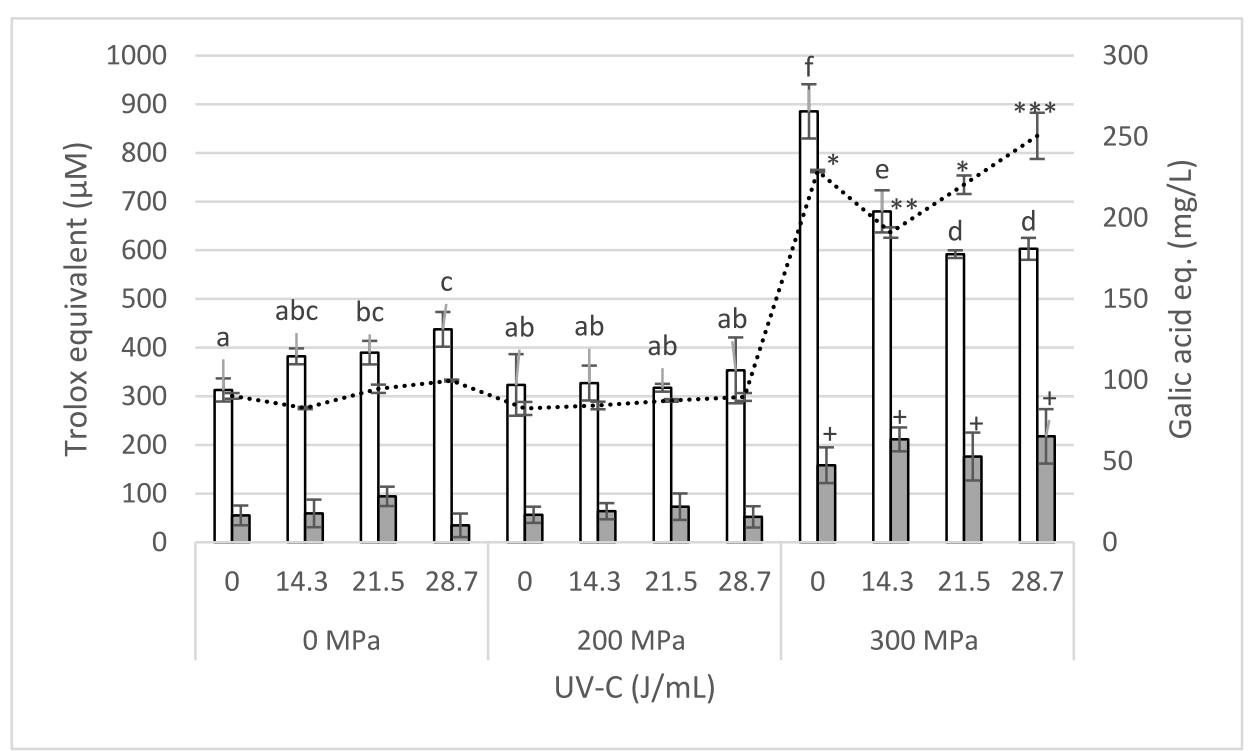

Fig. 6. Antioxidant capacity and total polyphenols of cloudy apple juice treated by UHPH at 200 and $300 \mathrm{MPa}$, or by different UV-C doses (14.3, 21.5 and $28.7 \mathrm{~J} / \mathrm{mL}$ ). Both technologies were also combined in the order UHPH $\rightarrow$ UV-C. Antioxidant capacity was measured by FRAP (white bars) and DPPH (grey bars) methods, the results were expressed as trolox equivalent $(\mu \mathrm{M})$. Antioxidant capacity was compared with the content of total polyphenols (dotted line) expressed as galic acid equivalent $(\mathrm{mg} / \mathrm{mL})$. Significant differences $(p<0.05)$ between samples means obtained by Tukey test divided according to the test, lowercase letters for differences in FRAP; plus symbol $(+)$ for differences in DPPH compared with the untreated control; and asterisks (*) for differences compared with the untreated control and between the samples treated by $300 \mathrm{MPa}$ of UHPH and the different combinations with UV-C. Error bars mark the standard deviation of the samples.

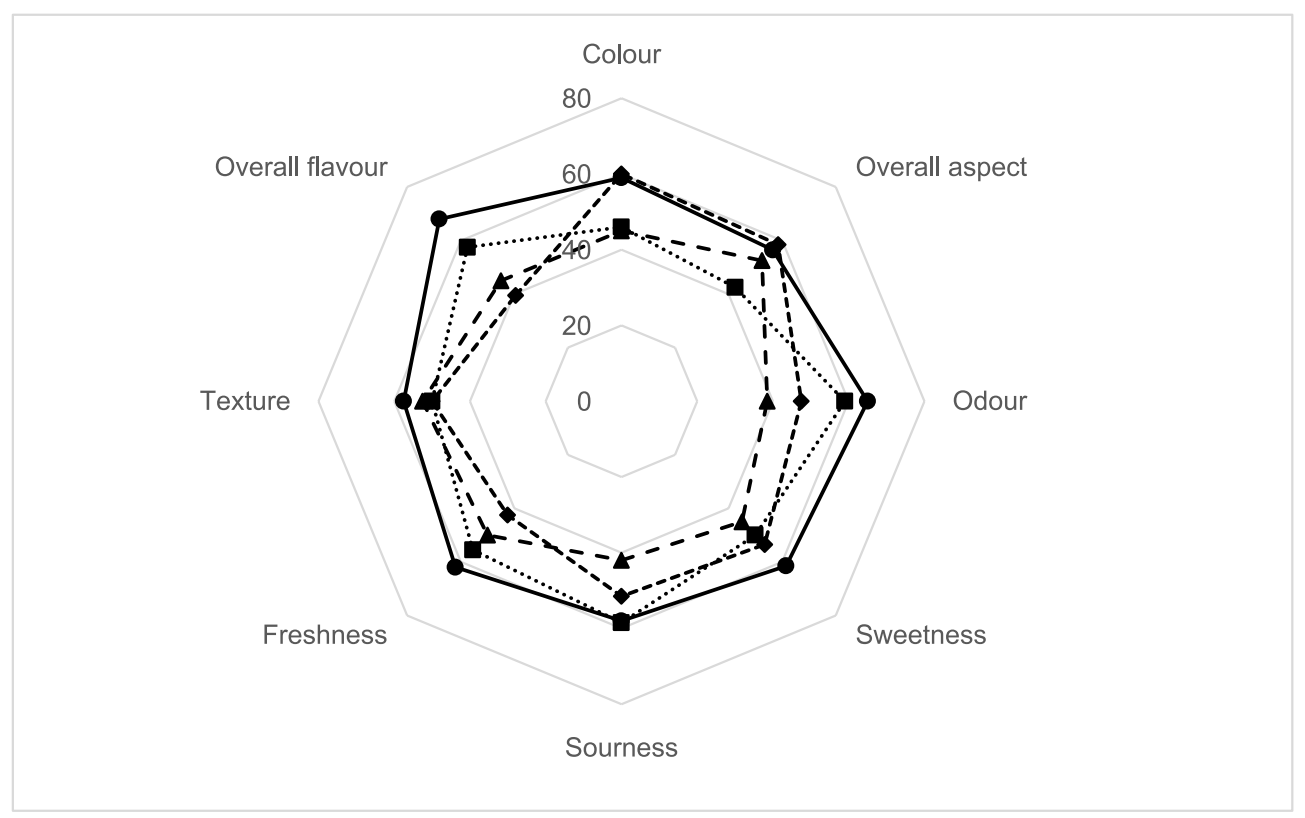

Fig. 7. Results of the sensory evaluation test. Samples of apple juice were scored in order of preference, and they were the non-treated control ( $\bullet$ ), processed by UV$\mathrm{C}$ at $21.5 \mathrm{~J} / \mathrm{mL}(\diamond)$, and processed by UHPH at $200 \mathrm{MPa}(\boldsymbol{\square})$ or $300 \mathrm{MPa}(\boldsymbol{\Lambda})$.

Table 3

Significant differences between samples in the sensory parameters of "odour" and "overall flavour". For a test of this magnitude the minimal significant difference (MDS) between the samples' scores had to be higher than 16.4. Samples were coded as A (raw juice), B (UV-C $21.5 \mathrm{~J} / \mathrm{mL}$ ), C (UHPH $200 \mathrm{MPa}$ ) and D (UHPH $300 \mathrm{MPa}$ ).

\begin{tabular}{llll}
\hline \multicolumn{2}{l}{ Odour MSD $>16.4$} & \multicolumn{3}{l}{ Overall flavour MSD $>16.4$} \\
\hline A-B & 17.5 & A-B & 28.5 \\
A-D & 26.5 & A-D & 23 \\
C-D & 20.5 & B-C & 18 \\
\hline
\end{tabular}

the raw juice in the other parameters related to taste (sweetness, sourness, freshness and texture). The treated juice that resulted the most similar to a raw product was the one treated by $200 \mathrm{MPa}$ of UHPH, though it scored the least on the parameter of overall aspects most likely because of its appearance due to the distribution of particles (Fig. 1) and colour (Table 2) together.

\section{Conclusions}

UHPH treatments at $300 \mathrm{MPa}$ were the best ones for processing cloudy apple juice from the physicochemical and enzymatic standpoint. It enhanced the antioxidant activity of juice and when combined with higher doses of UV-C there was an increment in the total content of polyphenols. This treatment could greatly reduce the activity of PME, and PPO activity was not detected. That along with the cloud stability from the reduction of particle size could improve apple juice stability overall. Although this survey focuses on the effect that these technologies have on the physicochemical, enzymatic and organoleptic properties of cloudy apple juice, some other research done by our group point out that UV-C could be a key factor in the preservation of apple juice 
from the microbial standpoint in inactivating bacterial and some fungal spores at low temperatures, which is something that UHPH is ineffective at. For these reasons it could be said that UHPH and UV-C are technologies that can complement each other when combined and applied to liquid foods in order to bring physiochemically and microbially stable foods with a low impact in their organoleptic properties and acceptation while preserving, or even making more available the polyphenol content and antioxidant capacity in fruit juices.

\section{CRediT authorship contribution statement}

J.N. Sauceda-Gálvez: Investigation, Formal analysis, Writing. I. Codina-Torrella: Methodology, Formal analysis. M. Martínez-García: Formal analysis. M.M. Hernández-Herrero: Conceptualization, Supervision. R. Gervilla: Conceptualization, Supervision, Funding acquisition. A.X. Roig-Sagués: Conceptualization, Supervision, Funding acquisition.

\section{Declaration of competing interest}

The authors declare that they have no known competing financial interests or personal relationships that could have appeared to influence the work reported in this paper.

\section{Acknowledgments}

The authors acknowledge the financial support received from the research project AGL2014-60005-R of the Spanish Ministry of Economy and Competitiveness. And the grant number 440526 given to Jezer Noé Sauceda Gálvez by CONACyT (Consejo Nacional de Ciencia y Tecnología, México) and from INAPI (Instituto de Apoyo a la Investigación e Innovación) of Sinaloa.

\section{References}

Benzie, I. F., \& Strain, J. J. (1996). The ferric reducing ability of plasma (FRAP) as a measure of "antioxidant power": The FRAP assay. Analytical Biochemistry, 239, $70-76$.

Betoret, E., Betoret, N., Carbonell, J. V., \& Fito, P. (2009). Effects of pressure homogenization on particle size and the functional properties of citrus juices. Journal of Food Engineering, 92, 18-23.

Bondet, V., Brand-Williams, W., \& Berset, C. (1997). Kinetics and mechanisms of antioxidant activity using the DPPH.free radical method. Lebensmittel-Wissenschaft und -Technologie- Food Science and Technology, 30, 609-615.

Bot, F., Calligaris, S., Cortella, G., Plazzotta, S., Nocera, F., \& Anese, M. (2018). Study on high pressure homogenization and high power ultrasound effectiveness in inhibiting polyphenoloxidase activity in apple juice. Journal of Food Engineering, 221, 70-76.

Cano, M. P., Hernandez, a., \& Ancos, B. (1997). High pressure and temperature effects on enzyme inactivation in strawberry and orange products. Journal of Food Science, 62, $85-88$.

Carbonell, J. V., Navarro, J. L., Izquierdo, L., \& Sentandreu, E. (2013). Influence of high pressure homogenization and pulp reduction on residual pectinmethylesterase activity, cloud stability and acceptability of lane late orange juice: A study to obtain high quality orange juice with extended shelf life. Journal of Food Engineering, 119, 696-700.
Chisari, M., Barbagallo, R. N., \& Spagna, G. (2007). Characterization of polyphenol oxidase and peroxidase and influence on browning of cold stored strawberry fruit. Journal of Agricultural and Food Chemistry, 55, 3469-3476.

Davies-Colley, R. J., \& Smith, D. G. (2001). Turbidity, suspended sediment, and water clarity: A review. Journal of the American Water Resources Association, 37, 1085-1101.

Donsì, F., Esposito, L., Lenza, E., Senatore, B., \& Ferrari, G. (2009). Production of shelfstable annurca apple juice with pulp by high pressure homogenization. International Journal of Food Engineering, 5.

Dumay, E., Chevalier-Lucia, D., Picart-Palmade, L., Benzaria, A., Gràcia-Julià, A., \& Blayo, C. (2013). Technological aspects and potential applications of (ultra) highpressure homogenisation. Trends in Food Science \& Technology, 31, 13-26.

Falguera, V., Pagán, J., \& Ibarz, A. (2011). Effect of UV-C irradiation on enzymatic activities and physicochemical properties of apple juices from different varieties. Lebensmittel-Wissenschaft und -Technologie- Food Science and Technology, 44, 115-119.

Ibarz, A., Pagán, J., Panadés, R., \& Garza, S. (2005). Photochemical destruction of color compounds in fruit juices. Journal of Food Engineering, 69, 155-160.

Koutchma, T. (2009). Advances in ultraviolet light technology for non-thermal processing of liquid foods. Food Bïoprocess Technology, 2, 138-155.

Krapfenbauer, G., Kinner, M., Gössinger, M., Schönlechner, R., \& Berghofer, E. (2006). Effect of thermal treatment on the quality of cloudy apple juice. Journal of Agricultural and Food Chemistry, 54, 5453-5460.

Orlowska, M., Koutchma, T., Kostrzynska, M., Tang, J., \& Defelice, C. (2014). Evaluation of mixing flow conditions to inactivate Escherichia coli in opaque liquids using pilotscale Taylor-Couette UV unit. Journal of Food Engineering, 120, 100-109.

Reverter-Carrión, L., Sauceda-Gálvez, J. N., Codina-Torrella, I., HernándezHerrero, M. M., Gervilla, R., \& Roig-Sagués, A. X. (2018). Inactivation study of Bacillus subtilis, Geobacillus stearothermophilus, Alicyclobacillus acidoterrestris and Aspergillus Niger spores under Ultra-High Pressure Homogenization, UV-C light and their combination. Innovative Food Science \& Emerging Technologies, 48, 258-264.

Saldo, J., Suárez-Jacobo, Á., Gervilla, R., Guamis, B., \& Roig-Sagués, A. X. (2009). Use of ultra-high-pressure homogenization to preserve apple juice without heat damage. High Pressure Research, 29, 52-56.

Sauceda-Gálvez, J. N., Roca-Couso, R., Martinez-Garcia, M., Hernández-Herrero, M. M., Gervilla, R., \& Roig-Sagués, A. X. (2019). Inactivation of ascospores of Talaromyces macrosporus and Neosartorya spinosa by UV-C, UHPH and their combination in clarified apple juice. Food Control, 98, 120-125.

Singleton, V. L., Orthofer, R., \& Lamuela-Raventós, R. M. (1998). Analysis of total phenols and other oxidation substrates and antioxidants by means of folin-ciocalteu reagent. Methods in Enzymology, 299, 152-178.

Suárez-Jacobo, Á., Gervilla, R., Guamis, B., Roig-Sagués, A. X., \& Saldo, J. (2010). Effect of UHPH on indigenous microbiota of apple juice. A preliminary study of microbial shelf-life. International Journal of Food Microbiology, 136, 261-267.

Suárez-Jacobo, Á., Rüfer, C. E., Gervilla, R., Guamis, B., Roig-Sagués, A. X., \& Saldo, J. (2011). Influence of ultra-high pressure homogenisation on antioxidant capacity, polyphenol and vitamin content of clear apple juice. Food Chemistry, 127, 447-454.

Suárez-Jacobo, Á., Saldo, J., Rüfer, C. E., Guamis, B., Roig-Sagués, A. X., \& Gervilla, R. (2012). Aseptically packaged UHPH-Treated apple juice: Safety and quality parameters during storage. Journal of Food Engineering, 109, 291-300.

Torkamani, A. E., \& Niakousari, M. (2011). Impact of UV-C light on orange juice quality and shelf life. International Food Research Journal, 18, 1265-1268.

Velázquez-Estrada, R. M., Hernández-Herrero, M. M., Guamis-López, B., \& RoigSagués, A. X. (2012). Impact of ultra high pressure homogenization on pectin methylesterase activity and microbial characteristics of orange juice: A comparative study against conventional heat pasteurization. Innovative Food Science \& Emerging Technologies, 13, 100-106.

Velázquez-Estrada, R. M., Hernández-Herrero, M. M., Guamis-López, B., \& RoigSaguès, A. X. (2019). Influence of ultra-high pressure homogenisation on physicochemical and sensorial properties of orange juice in comparison with conventional thermal processing. International Journal of Food Science and Technology, 54, 1858-1864.

Velázquez-Estrada, R. M., Hernández-Herrero, M. M., Rüfer, C. E., Guamis-López, B., \& Roig-Sagués, A. X. (2013). Influence of ultra high pressure homogenization processing on bioactive compounds and antioxidant activity of orange juice. Innovative Food Science \& Emerging Technologies, 18, 89-94. 